\title{
MUJERES Y CULTURA EN AMÉRICA: UNA SOCIEDAD HECHA DE RELACIONES. APUNTES PARA UN NUEVO ENFOQUE METODOLÓGICO
}

\author{
María Antonia BEL BRAVO
}

Recibido: $12 / 06 / 2012$

Aceptado: 24/09/2012

RESUMEN: En un trabajo anterior ${ }^{1}$, concluía yo que las mujeres, tanto indígenas como españolas que habitaron el nuevo continente, fueron en gran medida las sintetizadoras de dos culturas diferentes, ambas con raíces profundas en sus propias tradiciones. En este artículo analizo algunos factores históricoantropológicos que hicieron posible este mestizaje cultural, de marcado carácter femenino: el empeño de la mujer por relacionarse y crear vínculos a través del lenguaje, la educación, el ámbito asistencial y, sobre todo, la familia como eje vertebrador de la nueva sociedad. En definitiva, trato de aproximarme al hecho indiscutible de cómo se impuso la autoridad femenina en el cambio social que se operó en aquellas tierras. Pero todo esto conlleva una "nueva manera de mirar" la Historia de las Indias, un nuevo enfoque historiográfico.

PALABRAS CLAVE: Autoridad femenina, Educación, Relaciones, Inculturación.

ABSTRACT: In previous work, I concluded that women, both indigenous and Spanish that inhabited the new continent were largely synthesizing two different cultures, both with deep roots in their own traditions. In this article I analyze historical and anthropological factors that made possible this cultural mixing of distinctly feminine: the commitment of women to interact and build links through language, education, health care setting and, above all, the family as backbone of the new society. In short, I try to approach the indisputable fact of how imposing the authority of women in social change that came over the land. But all this leads to a "new view" History of the Indies, a new historiographical approach.

KEYWORDS: women Authority, Education, Relationships, Inculturación.

\section{INTRODUCCIÓN}

La aculturación, como sabemos, es un fenómeno resultante de la agregación a un sistema cultural, ya existente, de otro o de varios elementos culturales en forma de rasgos aislados o complejos, que al incorporarse al sistema modifican los

${ }^{1}$ Bel BRAvo, M.A (2012): «La mujer como generadora de una nueva cultura. Una lectura diferente de la colonización española de América», Hispania Sacra, vol. LXIV, n 129, pp.211-235. 
contenidos de su estructura cultural sin transformar directamente su estructura institucional y social. Sin embargo, en el caso de América es preferible hablar de inculturación, ya que con este término se expresa no sólo el encuentro de dos culturas, sino también el importante encuentro de una cultura, la indígena, con el Evangelio, que no es solamente una cultura, sino una religión y que, prácticamente, lo impregnó todo y supuso una gran transformación de las estructuras institucionales existentes.

A consecuencia del encuentro étnico y cultural, las mujeres adquirieron importancia como refundidoras de viejas tradiciones e impulsoras de novedades generadas por los problemas que planteaba la vida cotidiana. Fueron las formadoras de una nueva sociedad en la que las indígenas conservaron hábitos y culturas domésticas prehispánicas y las españolas aportaron sus propias costumbres., traídas de la Península Ibérica.

Unas y otras tradiciones impregnaron la vida de las tierras americanas de un peculiar carácter mestizo, muy diferente de cuanto los españoles habían dejado al otro lado del océano. El habla popular, el vestido, la alimentación, algunas prácticas curativas y el orden doméstico-familiar mostraban claros rasgos de su raigambre americana. Y cuestiones de clara aculturación que, en principio, parecían únicamente relacionadas con el marco familiar -prácticas dietéticas y curativas, devociones piadosas, etc.- se van a proyectar, a través de la mujer y la familia, a toda la sociedad.

Sin embargo, al encarar este reto del mestizaje, en gran medida femenino, me encontré con que tanto el individualismo metodológico, como el estructuralismo, o cualquier otro enfoque historiográfico conocido, resultaban aproximaciones insuficientes para entender la nueva sociedad que generaron las mujeres en América. En este sentido, Pier Paolo Donati proponía un enfoque alternativo para el análisis de la realidad social: el llamado "enfoque relacional" ${ }^{2}$ más adecuado, a mi juicio, para esta tarea. Pues bien, es este enfoque el que voy a aplicar en el presente estudio acerca de la intervención femenina en la colonización y evangelización de América. Intervención que fue en gran medida la protagonista del cambio social operado en aquellos territorios, ya que el contacto con extranjeros, y el préstamo tomado de ellos, constituye la principal rueda conductora del cambio histórico.

2 Véase su libro Repensar la sociedad. El enfoque relacional (2006). Madrid, Ediciones Internacionales Universitarias. 


\section{EL ENFOQUE RELACIONAL}

Pero ¿qué es una "relación social”? ¿Qué significa "estar en relación” con otras personas? ¿Qué quiere decir que los hechos sociales son "realidades relacionales"? Estas preguntas son, en mi opinión, la puerta de entrada a uno de los enfoques más interesantes del panorama historiográfico actual. Para quienes ya conocen el planteamiento sociológico de Donati éstas son, sin duda, consideraciones superfluas. Pero para quienes se sitúan por primera vez ante este tipo de discurso, tal vez sea útil dedicarles cierta atención.

"Estar en relación" significa atenerse a un modo específico de conducta: la reciprocidad. Para Donati, la reciprocidad es una categoría central de lo social. Con el término "reciprocidad" se refiere a un intercambio simbólico que tiene lugar en un circuito de donaciones en ambas direcciones. Relacionarse implica dar y recibir.

La reciprocidad lleva consigo tres momentos distintos: don, aceptación y contraprestación. Esta última consiste en un equivalente simbólico referido al uso $\mathrm{y}$, por tanto, no mensurable en dinero o en otros parámetros abstractos del valor. "Una sociedad caracterizada por la reciprocidad generalizada es más eficiente que otra desconfiada, por la misma razón por la que la eficiencia del dinero es mayor que la del trueque"3. La sociedad está hecha de relaciones, no de individuos. Y una relación social es aquella que conecta sujetos sociales en la medida en que actualiza o genera un vínculo entre ellos.

Podemos decir entonces que una relación social tiene una triple semántica:

$\checkmark$ es una referencia significativa.

$\checkmark$ es un vínculo entre personas

$\checkmark$ es también el resultado de la acción recíproca entre los sujetos implicados.

Gestionar relacionalmente los problemas requiere tener en cuenta lo funcional, lo no funcional y las relaciones entre ambos. De esa forma se considera -y se trataa los sujetos destinatarios de la intervención como los auténticos protagonistas. Toda relación implica un intercambio, es decir una acción recíproca en la que algo pasa del yo al otro y viceversa, lo cual genera cierto vínculo entre ellos. Es preciso tener presente que los intercambios posibles no son sólo los económicos. El intercambio social puede adoptar otras formas, otros contenidos, otros tiempos y

${ }^{3}$ Ibid, p. 13. 
convertirse así en núcleo generador y motor propulsor de muy diversos tipos de relación social.

Para la comprensión del cambio social ya no sirven esquemas causales unilineales o multilineales. Más bien habría que hablar de una causalidad históricosocial de carácter circular. Esto no significa convertir a la Historia en relativista sino en relacional. El cambio social consiste entonces en un modo diverso de configurar, en y según el tiempo, las relaciones que constituyen un fenómeno o una entidad social observable. Ya no se trata únicamente del tránsito de sociedades tradicionales a sociedades modernas. Tampoco significa un estado de evolución o de "progreso" social. Simplemente es un modo diverso de ordenar relacionalmente en el tiempo los elementos y las relaciones entre sí. Para que se de un cambio social no basta con un nuevo elemento (por ejemplo una nueva tecnología) o una nueva relación social en sí y por sí (por ejemplo en los estilos de vida), sino que es necesaria una completa y diferenciada forma de relación entre las relaciones y los elementos que la componen. Esta es la nueva comprensión del cambio social ${ }^{4}$.

Cada forma de intercambio social tiene, según Donati ${ }^{5}$, su propia estructura interna, es decir, elementos o componentes que le son propios y que le distinguen de otras formas de vinculación y dependencia. Esos componentes son: los medios adecuados, las metas específicas, las reglas propias y los valores que dan sentido a cada forma de acción recíproca.

Este fue en gran medida el caso de la América colonial, donde no cabe hablar de sociedad estamental rígida y sin fisuras, aunque esa fuese la organización social vigente en la Península, porque olvidaríamos que la etnia desempeñó un papel determinante en los cambios concretos de la vida cotidiana y, por ende, en el cambio histórico propiamente dicho. En las Indias las mujeres tuvieron la oportunidad de participar en el surgimiento de una nueva sociedad que, a pesar de los rasgos señoriales que los conquistadores y primeros pobladores intentaron implantar, gozó de una gran movilidad y les brindó oportunidades en el espacio público que a sus contemporáneas peninsulares les estaban vedadas. Eso sí, sin abandonar en ningún momento sus obligaciones en el ámbito privado.

El radio de acción femenino no estaba limitado a lo que el siglo XIX llamará "la esfera privada" de las relaciones domésticas; a pesar del rebajamiento gradual del trabajo femenino a tareas subalternas y la paralela pérdida de rango y derechos en

4 Cualquier teoría que intente acceder, según Donati, a esta comprensión debe tener las características de lo "relacional", ob. cit., p.192.

${ }^{5}$ Ibid, p. 19. 
cuanto a la trasmisión y gestión de la propiedad, las mujeres en América ocupan un terreno público relevante en la construcción, si no del Estado propiamente dicho, si de la sociedad. De hecho, en los siglos XVI-XVIII, nadie habría colocado a la familia y las relaciones familiares, ni a la profesión religiosa o el sentimiento de lo divino en el ámbito de la privacidad y la elección individual.

En este sentido, Guillermo Bonfil, en su investigación sobre Cholula ${ }^{6}$, nos ha legado varias ideas que pueden contribuir a romper con esquemas predeterminados y llevarnos a un terreno más fecundo. En lugar de fijarnos en la presencia o ausencia de determinados rasgos culturales, como pueden ser el idioma o el origen de la canela y el clavo, Bonfil destaca la importancia de lo relacional, metodología aplicada en este artículo, así como de los elementos de la organización social, como ámbitos donde debe buscarse lo "indígena".

En el último capítulo de su libro, que lleva el sugerente título de "Cholula problema", Bonfil desarrolla estas ideas y discute los problemas inherentes a las categorías basadas en las oposiciones binarias. Para Bonfil, Cholula ya no es "población indígena, al menos en los términos en que comúnmente se entiende esa categoría"; ; se trata de "una pequeña ciudad industrializada, con una cultura predominantemente mestiza (idioma, indumentaria, alfabetismo, etcétera), con una economía capitalista, pero con un complejo de instituciones religiosas tradicionales de carácter corporativo", que, según las ideas más usuales, debieron ser las primeras en desaparecer a lo largo del proceso histórico de la ciudad -de hecho muchas de ellas desaparecieron por su conexión con una cultura de muerte- ${ }^{8}$. Sin embargo, su cuestionamiento del "pensamiento binario y simplista" lo conduce a la vez a afirmar que "Cholula se conserva indígena". Es en este cuestionamiento del pensamiento binario y simplista donde estoy de acuerdo con él, aunque no comparto sus conclusiones en lo que a México se refiere ${ }^{10}$, porque la cultura occidental nunca trató de construir un México ajeno a su realidad. En este sentido, la actividad de las mujeres fue decisiva.

\section{UN MODO FEMENINO DE MIRAR EL MUNDO}

A finales del siglo $\mathrm{XV}$, cuando los pueblos ibéricos iniciaron su andadura por

\footnotetext{
${ }^{6}$ BonfIL, G. (1976), Cholula: La ciudad sagrada en la era industrial, México, UNAM, Instituto de Investigaciones Históricas.

${ }^{7}$ Ibid, p. 256

${ }^{8}$ Ibid, p. 257

${ }^{9}$ Ibid, p. 263

${ }^{10}$ México profundo. Una civilización negada (1991). México, Alianza Editorial.
} 
los mares del mundo, muy pocas cosas habían cambiado para las mujeres respecto a épocas anteriores, la Edad Moderna con su afán imitativo -no olvidemos lo que significa Renacimiento-, había heredado el modelo patriarcal de sociedad que se gestó en la Antigüedad, y quedó fijado por el Derecho Romano, olvidando en gran medida los magníficos logros introducidos en el Medievo por algunos de los Derechos Germánicos.

Por otra parte, la literatura moral de la época se encargó de fijar las normas por las que se debían regir las mujeres, siempre subordinadas al varón, aunque a estas alturas de la investigación en temas de Historia de las mujeres es preciso señalar importantes diferencias entre unos autores y otros ${ }^{11}$, ya que se oscila entre la misoginia exacerbada de un arcipreste de Talavera que no encuentra virtud alguna en las mujeres, y el talante vanguardista e inteligente de algunos humanistas que, como Erasmo, supieron reconocer que por ejemplo Catalina de Aragón era más culta e inteligente que su famoso marido Enrique VIII.

Aún así, la opinión más extendida era que el destino ideal para ellas consistía en el convento o en el matrimonio, las solteras constituían una anomalía y las viudas se contemplaban con alguna prevención por el grado de autonomía que podían alcanzar. Así pues, el ámbito de desarrollo de estas obligaciones propias de la mujer era la familia, por ello hay múltiples tratados sobre esta institución ${ }^{12}$, que era la que podía asegurar una sociedad sana y sin problemas. En Indias, la presencia de las mujeres aumentó cuando las conquistas de México y Perú dieron paso a la fundación de ciudades y a una fase colonizadora y evangelizadora de mayor arraigo en la que la institución familiar estuvo llamada a representar el clásico papel de estabilización. Como bien sabemos los historiadores de la familia, no se puede pretender una sociedad mejor que las familias que la componen.

Podríamos decir que en muchos casos fueron las "obligaciones privadas" las que, trasladadas al espacio público americano, generaron una sociedad que rompió moldes. Por ejemplo, en el caso de las múltiples encomenderas se vio claro la aplicación del esquema doméstico-familiar a la gestión y dirección de las encomiendas $^{13}$, tanto en sus aspectos económicos como sociales y evangelizadores.

${ }^{11}$ Véase mi libro Bel Bravo, M.A. (2009) Mujer y cambio social en la Edad Moderna, Madrid, Encuentro. Véase también Morant, I (2002), Discursos de la vida buena Matrimonio, Mujer y Sexualidad en la Literatura Humanista, Madrid, Cátedra.

12 De nuevo remito al lector a otra obra mía Bel Bravo, M.A. (2000) La familia en la Historia, Madrid, Encuentro.

${ }^{13}$ Es el caso de las hermanas Gamiz, dos gienenses con propiedades en su provincia de origen y en la Nueva España, que administraron personalmente. Es interesante comprobarlo leyendo su 
En este sentido, es muy interesante y suscribo plenamente lo que explica José Andrés Gallego ${ }^{14}$ acerca del sello femenino, familiar, que tienen las distintas sociedades filantrópicas inglesas del siglo XIX, aunque, como en el caso de este trabajo, ese sello es posible rastrearlo mucho antes. La cuestión es que esto nos permite hablar de autoridad femenina.

¿Por qué autoridad femenina y no autoridad sin más? ¿Por qué hacer visibles y dar valor a los saberes de las mujeres? ¿Por qué empeñarse en que se reconozcan como saberes de las mujeres, y no "simplemente" como saberes, independientemente de cuál sea su origen? Porque no hay autoridad sin adjetivación: hay autoridad femenina o autoridad masculina, según encarne una mujer o un hombre. Y femenina porque, para una mujer, el referente de su libertad es otra mujer puesto que sólo otra mujer puede ser la mediación con la realidad.

La necesidad de hacer visibles los saberes de las mujeres tiene que ver con un criterio de realidad, de verdad que es el que lo exige. El mundo es uno y los sexos son dos; a esa evidencia corresponde que el conocimiento, los saberes, los modos de estar en el mundo se expresan siempre a dos voces, en masculino y en femenino $^{15}$. La incapacidad del esquema patriarcal de aceptar esa evidencia conduce -en el mejor de los casos- a la confusión y al empobrecimiento y -en el peor- al error, a vivir en una fantasía inexistente. Así que nombrar el mundo en femenino y en masculino es una exigencia epistemológica.

Hacer visibles, darles valor a las experiencias y los saberes que las mujeres han llevado y llevan al mundo y a la educación es reconocer autoridad femenina. Es poner a disposición de las niñas y las mujeres el caudal de conocimiento, con capacidad de hacer cultura, que es su herencia y en la que pueden apoyarse para crecer (ya sea aceptando, transformando o rechazando lo existente). Y es un modo de enseñar la libertad a las niñas y a las jóvenes. Porque, como ya dijo con sabiduría una mística medieval, cada cosa se aprende con su igual, así que si queremos apoyar la libertad de las niñas hemos de tener en cuenta que ésta "no se alcanza estancándose en la opresión y en la miseria sino, solamente, con la libertad"16.

testamento, Archivo Histórico Provincial de Jaén, legajo 740, fol. 909 y ss. Protocolos de Juan de Morales.

${ }^{14}$ Recreación del Humanismo desde la Historia (1994), Madrid, Actas, p. 67-68.

15 Rivera Garretas, M. (2005), La diferencia sexual en la Historia, Valencia, Universidad de Valencia, p.66.

${ }^{16}$ Ibid. p. 67. 
¿Para qué puede servir a los varones, esta apuesta por visibilizar los saberes de las mujeres? No estoy segura, porque no me es posible tener más experiencia que la de ser una mujer, pero pienso que puede ser importante, al menos en dos aspectos (relacionados, por otra parte). Les permitiría tener una visión más adecuada y más realista del mundo, del conocimiento y de otras formas de relacionarse con él; formas no basadas en la fuerza y el poder sino en el reconocimiento y la confianza, en el amor. Hace ya más de dos mil años que Aristófanes, comediógrafo griego, escribió "Lisístrata" y "La asamblea de mujeres", en donde afirmaba que el gobierno de las ciudades (gobernadas hasta aquel momento siempre por hombres, desde luego) sería exitoso si estuviera en manos femeninas, pues son ellas las que en realidad conocen como educar y llevar una buena economía, además de rechazar la guerra que las despoja de hijos y esposos. Un adelantado para su tiempo, qué duda cabe.

Conocer y reconocer los saberes de las mujeres les podría permitir a los niños y a los hombres aprender de ellas, de lo que estimen que es valioso, y, sobre todo, les podría dar un referente de alteridad, que está a su lado, que no es carente, ni dependiente, ni en relación de jerarquía, pero que tampoco los quiere desplazar, ni quitarles nada. Lo que sería un hallazgo revolucionario para la convivencia, en el aprendizaje siempre difícil del vivir bien consigo y con las y los demás.

Una de estas formas "apropiadas" de estar en el mundo para las mujeres es su opción por el saber de la experiencia, el saber contextual, en contacto con lo concreto. Esa preferencia por el saber de la experiencia, cuando se traduce en materiales, facilita ofrecer lo que se ha llamado el "conocimiento encarnado"; es decir, presentan el conocimiento ligado siempre a las personas, no desvinculado de sus experiencias, sus necesidades. Es desde ese vínculo desde el que se extienden los hilos para adentrarse en los conceptos, en los elementos, estructurales de la realidad, en la comprensión de las dimensiones políticas, económicas, religiosas, sociales, de la vida. Ese vínculo, por otra parte, sostiene su capacidad pedagógica, la posibilidad de encontrar eco en la experiencia de quien lee, de quien aprende, de las alumnas y de los alumnos.

Abordar los saberes cotidianos, que están más en la experiencia de las mujeres que en la de los hombres. Hacer visibles y presentar como objeto de aprendizaje esos saberes que aplicamos de manera permanente en nuestra vida, en la mayor parte de los casos elaborados y transmitidos por mujeres, que son fundamentales para la calidad de nuestra vida, pero que son "invisibles" por estar excluidos del bagaje de conocimientos "dignos" de ser enseñados: la alimentación y los saberes que implica; la atención que necesita una persona cuando está enferma; el cuidado 
de los espacios comunes; el valor de las relaciones, etc. Resumiendo se podría hablar de cuatro rasgos fundamentales en el estilo educativo femenino:

1. "Pasión por hacer viable el saber a cada una y a cada uno, atención a la singularidad de cada persona concreta y singular. Ese es el principio básico de la educación" ${ }^{\prime 1}$. Lo que se descubre con las maestras, y con las mujeres en general, que fueron a Indias es que sus enseñanzas servían para la vida, es decir, para que cada criatura pudiera seguir creando su propia singularidad y con su capacidad y, así cada cual fuera dejando en el mundo la huella de su presencia insustituible.

2. Sentido común para partir de la realidad y para saber adaptarse a cada situación concreta y cambiante. Es decir: elaborar una teoría pedagógica a partir de la experiencia. Ése es un camino distinto al que sigue el pensamiento académico, que es masculino: la teoría pedagógica se desliga de la experiencia pretendiendo convertirla en conocimiento científico, válido para todo y para todos gracias a que se le despoja de lo concreto, de todo lo que lo conecta con realidades contextuales y singulares.

3. El arte de la mediación, ese don para crear vínculos donde hacen falta; mediación que sólo es posible amando la relación, buscándola, también en lo que tiene de conflicto.

4. El placer del trabajo bien hecho, por encima de la búsqueda de reconocimiento. La gratificación hay que buscarla en la concordancia interna y no tanto en el exterior. "Como maestra sé que nuestros monumentos están vivos y se pueden reconocer en cada hombre o mujer que sabe vivir humanamente" ${ }^{\text {. }}$. En este sentido, se entiende mejor el epígrafe siguiente.

\section{LA FUERZA DE LOS LAZOS FAMILIARES}

El universo familiar se convierte, por tanto, en uno de los terrenos más apropiados para captar, por una parte, la actividad, las estrategias y los poderes informales de las mujeres, y, por otra, su lento reconocimiento y expresión como sujetos portadores de derechos. No se piense, por lo demás, en familias muy numerosas. El hecho de que la fecundidad fuera natural y no haya rastro de contracepción no empequeñece los efectos de la elevada mortalidad infantil. No era poca la gente que aludía, cuando hacía falta, a la crecida familia que tenía, como se

17 Montoya Ramos, M (2002), Escuela y Educación ¿hacia dónde va la libertad femenina? Madrid, 451 Editores, p. 27.

${ }^{18}$ Ibid 
lee en la representación de los alcaldes ordinarios de Jujuy, en el Tucumán rioplatense, en $1778^{19}$; por haberme cargado de hijos, dirá mejor Juliana del Castillo, vecina de Piura (Perú), al quejarse de que su esposo la había abandonado cinco años atrás ${ }^{20}$. Pero, a la hora de concretar el número de hijos, rara vez pasaban de cinco.

Pasado siglo y medio, en los padrones de habitantes que ordenó elaborar Lorenzana en 1768, siendo arzobispo de Méjico, llama la atención el número enorme de matrimonios que no tenían hijos, fueran españoles o indios. En el pueblo de San Felipe el Grande, por ejemplo, de los doscientos matrimonios que se empadronaron, sólo sesenta y tres tenían hijos que vivieran con ellos, y de esos, tres los que más. Y no hay que pensar en que la razón radicaba en que se emanciparan muy jóvenes (aunque en efecto sucediera) porque los hijos que vivían con sus padres iban desde los de pecho hasta los veinte años. Aparte había treinta y nueve viudos y viudas, nueve de los cuales vivían con algún hijo. Y lo mismo ocurría en los demás pueblos de la jurisdicción. En toda ella no había una sola familia indígena que tuviera más de tres. Había, sí, algunos hogares que no eran indios y que contaban con más hijos. Pero rara vez pasaban de cuatro ${ }^{21}$.

Por otra parte, la familia ocupó un puesto privilegiado en la enseñanza de la Iglesia durante los siglos XVI a XVIII. En realidad lo ha ocupado siempre. El Catolicismo -guste o no- es pues el referente más acertado para comprender cabalmente los modos de pensamiento en la época escogida para este trabajo. Logró que la familia de suyo prefigurara la cohesión interna y la "calidad moral" la expresión vale para la época- de la sociedad entera. Respecto a esto último, y dicho de otro modo, en diversas maneras se produjo un "acoplamiento" entre la realidad social y la filosofía dominante -"concepción vital", "interpretación de la existencia"-. De este modo, las funciones esenciales que desempeñaba la familia no pasaron inadvertidas a pensadores y reformadores y, gracias a éstos, tampoco a las autoridades políticas ${ }^{22}$. Su suerte se consideraba esencial para el bienestar de la

${ }^{19}$ Representación de don Miguel de Indabury y don Manuel Sánchez de Bustamante, 22 de octubre de 1778, AHN/C, leg. 20.373, exp. 1, pieza 23, f. 25v.

${ }^{20}$ Querella criminal de Juliana del Castillo, ADPi, Corregimiento: Causas criminales, leg. 56, exp. 1.155 (1764), s.f.

${ }^{21}$ Véase. "Padron de los Naturales que hay en esta Cabesera de San Felipe el Grande..." y "Copia del Padrón Anual y General que contiene todas personas y feligreses de esta feligresía de San Phelipe el Grande...", АHAM, Fondo del siglo XVIII, caja de 1768 bis.

${ }^{22}$ Por ejemplo, los llamamientos de autores como Martín González de Cellorigo a comienzos del siglo XVII, señalando los impedimentos para el matrimonio y la formación de la familia en la raíz de muchos de los problemas sociales y económicos que aquejaban a la monarquía hispana —según ya 
sociedad y, en caso de ser detectado algún problema, se adoptaban medidas para garantizar su buena salud.

Respecto a la cohesión social, señalaba yo en otro trabajo ${ }^{23}$ que la vía alternativa de aproximación propuesta nos sitúa ante el papel ético -moral equivale a lo mismo, en la España y América modernas- y educativo de la familia, por medio de la cual se conserva y transmite un sistema de valores que confiere a las relaciones entre los individuos el carácter específico de la época. Al mismo tiempo, la sociedad quizás hallara en la familia uno de los mecanismos de control más eficaces para salvaguardar el orden establecido, lo cual es importante si consideramos que nos ocupa un período de nuestra historia caracterizado por la debilidad institucional de los sistemas de seguridad.

Por otro lado, se ha de tener en cuenta que, por familia, no se entendía el núcleo formado por padres e hijos; se trataba más bien de un término relativamente impreciso, adaptable a realidades diversas; se aplicaba, en último término, al conjunto de personas que dependían del que hacía cabeza -"cabeza de familia"- y habitaban bajo su mismo techo. Así, la familia de don Raimundo de Lantery -el comerciante saboyano de Cádiz estudiado por Manuel Bustos- la componían en 1685 la esposa, los dos hijos, una hija, un hermano, un sobrino y un paisano originario de Niza que se le había sumado en un viaje ${ }^{24}$. En 1760, Carlos III señalaría expresamente el número de familia, o sea de personas que habían de componer la que llevara a Nueva España el marqués de Cruillas, como nuevo virrey, y enumeró a "la marquesa, dos hijos, una hija, dos sobrinos, un secretario, un capellán, un médico, seis individuos para mayordomo, caballerizo y gentilhombres, seis pajes, dos ayudas de cámara, ocho individuos para cocina, repostería y servicio interior de la casa y seis mujeres" ${ }^{25}$.

hemos expuesto en otro libro-, provocaron que en 1622, y a instancias del Conde-Duque de Olivares, la Junta de Reformación propusiera una política catalogable como verdaderamente "familiar" en la época. Se trataba de una serie de medidas destinadas a facilitar el matrimonio, la fecundidad y la formación de la familia. Para ello se limitaba la dote y se encomendaba a los órganos de beneficencia que constituyeran las de muchachas huérfanas o pobres; se promulgaron exenciones impositivas y otros privilegios especiales para recién casados y todos los que tuvieran más de seis hijos varones; se establecieron ciertas penalizaciones para quienes no estuvieran casados a los veinticinco años; etc. Véase MARTIN RodríGueZ Manuel (1984): Pensamiento económico español sobre la población. Madrid, Pirámide, pp. 259-266.

${ }^{23}$ La familia en la Historia, ob. cit., véase capítulo VI: En busca de la estabilidad social.

24 Bustos Rodriguez, M. (1983), Un comerciante saboyano en el Cádiz de Carlos II: las Memorias de Raimundo de Lantery. 1673-1700. Cádiz, Caja de Ahorros de Cádiz, p. 217.

${ }^{25} \mathrm{Sin}$ firma, a José Ignacio de Goyeneche, 3 de mayo de 1760, AGI/M, leg. 1.507a, exp. Año de 1766 a $67 \ldots$, s.f. 
Fuera como fuese, la familia gozó de una importancia singular durante la época moderna: es la célula básica de la sociedad, y la constitución de ésta, incluida su naturaleza política, es una proyección analógica de la relación familiar. Así lo hicieron ver constantemente los tratadistas de la época. Esta conclusión de la filosofía perenne se percibe con claridad en las obras del momento: la familia se entiende como el pilar más importante del Estado Moderno o, si se prefiere, el Estado como una suma de familias, correspondiendo a la autoridad del monarca su justo gobierno como al cabeza de familia el del grupo doméstico.

Esta es la teoría. En la práctica no parece descabellado suponer que la peculiar relación que la mujer guarda con la vida generó en ella unas disposiciones particulares que la hicieron idónea para las funciones que iba a desempeñar durante tantos siglos. Se entiende, pues, que desarrollara especialmente determinados hábitos intelectuales y capacidades: aquellos que tienen que ver directamente con la práctica. Frecuentemente su conocimiento se ha movido dentro del ámbito de lo que Aristóteles llamaba experiencia, puesto que además se le negó el acceso a la formación intelectual y al conocimiento científico.

Esto explicaría, por ejemplo, ese curioso fenómeno de la "intuición femenina", de ese ver sin necesidad de discurso, esa inteligencia que se ha denominado poliédrica $^{26}$ porque es capaz de tener en cuenta todos los planos de la vida humana: no sólo los intelectivos sino también los afectivos, que en tantos momentos condicionan de forma mucho más intensa a la persona ${ }^{27}$. Y los hábitos culturales, según Aristóteles, constituyen una segunda naturaleza que conforma a la persona ${ }^{28}$.

Por otra parte, en las sociedades preindustriales la familia era una manera de subsistir; sus formas predominaban en las estructuras organizativas artesanas y empresariales: prevalecían el taller familiar y el trabajo doméstico, entre otras cosas porque la propia economía tampoco exigía más. El traspaso de los bienes se llevaba a cabo, en gran medida, mediante la dote y los sistemas de herencia, esto es, por cauces relacionados con la familia. Ésta desempeñaba un papel de primera importancia en el mantenimiento de un orden social cuya jerarquía parece depender, entre otros principios, del respeto hacia los mayores y los antepasados ${ }^{29}$, como veremos en el siguiente epígrafe.

\footnotetext{
${ }^{26}$ María Antonia Bel Bravo, La mujer..., ob. cit.

${ }^{27}$ Véase SEGURA, C. (2000) «El ideal kantiano de la paz perpetua» en Hacia la no violencia, una cuestión de educación, Madrid, Sanz y Torres.

${ }^{28}$ Ampliamente desarrollado por María Antonia Bel Bravo, La mujer..., ob. cit., pp. 33-40.

${ }^{29}$ Véase CASEY, J. (1991), «La familia en la Andalucía del Antiguo Regimen», en Historia 16, no 57.
} 


\section{GENERADORAS DE CULTURA}

El siglo de las luces fue precedido, en la historia de los libros ${ }^{30}$, sobre todo en la historia de la tipografía, la impresión y la venta de libros, por el de las viudas: el XVII, el siglo más sustancioso respecto a la calidad y cantidad del trabajo de mujeres que, esposas de dueños de imprentas y ya muertos éstos, se hicieron cargo del negocio de su marido y participaron en la construcción de México en tanto ciudad ilustrada. Lo mismo sucedía en la metrópoli donde es llamativo el número de hermanas, hijas o viudas que, habiendo aprendido el oficio en sus casas, se convierten en auténticas expertas de la impresión ${ }^{31}$.

Algunas de estas mujeres, además de ser dueñas de imprentas ${ }^{32}$, lo fueron también de grandes librerías; caso ejemplar el de Paula Benavides viuda de Calderón, que destacó entre los impresores y libreros del siglo XVII novohispano. Estas mujeres, viudas en su mayoría y varias de ellas herederas de viudas que a su vez enviudaban, son de importancia primordial en la formación de las familias impresoras de la Nueva España y cumplen una función de primer orden en la historia de la imprenta en México que, iniciada en el XVI, se solidifica en el siglo XVII.

Juan Pablos, primer impresor de la Nueva España, recibió de Juan Cromberger 120.000 maravedís destinados tanto a la compra de la prensa, tinta, papel y otros aparejos, como a los gastos del viaje que emprendería con su mujer y dos acompañantes más. El costo total de la empresa fue de 195,000 maravedís o sea de 520 ducados. Juan Pablos, de origen italiano cuyo nombre, Giovanni Paoli, conocemos ya castellanizado, llegó a la Ciudad de México junto con su esposa

\footnotetext{
${ }^{30}$ Sobre el tema, Juan José de Eguiara y Eguren, Bibliotheca Mexicana (1er. tomo, 1755); José Mariano Beristain DE SouZA, Biblioteca Hispano-Americana (1er. tomo, 1816); José Joaquín ICAZBALCETA, Bibliografía Mexicana del siglo XVI (1886); Nicolás León, Bibliografía Mexicana del siglo XVIII (1902-1903); Vicente de P. ANDRADE, (1899), Ensayo bibliográfico del siglo XVII, México, Imprenta del Museo Nacional; José ToRiBIo MedinA, (1989), La imprenta en México (15391821), México, UNAM; Francisco GonzÁLEZ de Cossío, (1952), La imprenta en México (15531820). 510 adiciones a la Obra de José Toribio Medina en homenaje al primer centenario de su nacimiento, México, Universidad Nacional de México.

${ }^{31}$ Véase Norton, F.J.: La imprenta en España. (1997), Madrid, Ollero y Ramos. También los muchos estudios que existen sobre provincias españolas concretas, por ejemplo el de María Dolores SÁNCHEZ CoBos, (2005), La imprenta en Jaén, 1550-1831. Jaén, Universidad.

${ }^{32}$ Véase Carolina Amor DE FouRnier, (1972) La mujer en la tipografía mexicana, México, La Prensa Médica Mexicana. Este libro es un breve y sustancioso compendio del tema que aquí interesa; es importante no sólo como antecedente de este tema sino como reflexión también acerca de las labores femeninas en las actividades públicas en la historia de México.
} 
Gerónima Gutiérrez, entre septiembre y octubre de 1539. Venían también con él Gil Barbero, prensista de oficio, así como un esclavo negro ${ }^{33}$.

Desde los preparativos del viaje de Europa a América, Juan Pablos, empleado en la casa impresora de Juan Cromberger en Sevilla, España, el nombre de una mujer figura ya en el primer documento histórico de la tipografía en México. Al firmar Juan Pablos en 1539 el contrato que durante diez años lo haría representante de Juan Cromberger en México, dice de su esposa: "que la dicha Gerónima de Gutiérrez, mi mujer, sea obligada a regir y servir la casa en todo lo que fuera menester, sin llevar por ello soldada ni otra cosa". A las labores caseras, aseguradas sin goce de sueldo -sin "soldada"-, las acompañarían de cerca las de la imprenta, realizadas por vez primera en México gracias a los "aparejos y papel y tinta" con los que Juan Pablos y Gerónima de Gutiérrez salieron de Sevilla, llegaron a la capital de la Nueva España y allí se establecieron.

De la primera etapa de la imprenta con denominación "en casa de los Cromberger" podemos citar las siguientes obras: Breve y más compendiosa doctrina christiana en lengua mexicana y castellana que contiene las cosas mas necesarias de nuestra sancta fe catholica para el aprovechamiento destos indios naturales y salvación de sus ánimas. Se cree que esta fue la primera obra impresa en México, el Manual de adultos del que se conocen las tres últimas páginas, editado en 1540 y mandado hacer por la junta eclesiástica de 1539, y La Relación del espantable terremoto que agora nuevamente ha acontecido en la ciudad de Guatemala publicado en 1541. A estos siguieron en 1544 la Doctrina Breve de 1543 destinada a todos en general; el Tripartito de Juan Gerson que es una exposición de la doctrina sobre los mandamientos y la confesión, y tiene como apéndice un arte de bien morir; el Compendio breve que trata de cómo se van hacer las procesiones, destinado a reforzar las prohibiciones de las danzas y regocijos profanos en las fiestas religiosas, y la Doctrina de fray Pedro de Córdoba, dirigida exclusivamente a los indios ${ }^{34}$. En 1563 la viuda de Juan Pablos, mayor y cansada, arrendó la imprenta a Pedro Ocharte casado con María de Figueroa, hija de Juan Pablos, que continuó la saga familiar.

Cuando acaba el siglo XVI varias viudas son dueñas y encargadas de estas propiedades y se han ido dando a conocer, en la trayectoria de la imprenta en México configurada en buena medida por la labor de estas mujeres. De sus talleres

${ }^{33}$ GARCía ICAZBAlCETA, J. (1954): Bibliografía mexicana del siglo XVI, México, FCE.

${ }^{34}$ Son datos que, aunque muy conocidos, me permito incluir en este artículo para reforzar el tema de la inculturación. 
tipográficos salían libros cuyo contenido, formato y finalidad eran similares a los de las otras imprentas puesto que todas estaban regidas por las mismas reglamentaciones del gobierno virreinal al servicio de la corona y de la Iglesia. Sobre esos materiales informa García Icazbalceta:

"La mayor parte de los libros impresos del siglo XVI fueron destinados, como era natural, a la instrucción de los indios, y así es que los hay en alguno de sus diversos idiomas, principalmente en mexicano, otros en castellano, y también en dos lenguas; la española y una de las indígenas. Los hay también en latín. Imprimiéronse muchos "Artes" para aprender idiomas del país, confesonarios, manuales de sacramentos, doctrinas y algunos tratados para uso de los colegios o de los misioneros, reglas y constituciones. El tamaño era de 80, 40 y folio común: la letra es gótica, romana, aldina, o mezcla de todas" ${ }^{35}$.

Así pues, las viudas impresoras, con los impresores de la época, hacen posible la política cultural dictaminada desde el poder civil y religioso, y la literatura impresa responde a los intereses de los dos gobiernos.

Además de las publicaciones que ya se han señalado y que la viuda de Calderón comparte con los otros impresores de su tiempo, ella se asigna particularmente una tarea: dar a conocer en México las noticias recibidas desde Europa y lo hace al publicar las primeras Gacetas que vieron la luz en la Nueva España. De estas Gacetas dice García Icazbalceta:

"La primera que conozco es de 1671 impresa por la viuda de Bernardo Calderón, y en 1687 comenzó a imprimirlas $\mathrm{D}^{\mathrm{a}}$. María de Ribera, heredera de la anterior, "con imprenta nueva de Amberes Plantiniana" como ella misma anuncia en una de sus gacetas. Tales relaciones sueltas, compuestas de noticias de Europa mezcladas con los estupendos prodigios, duraron por lo menos hasta 1721, por varios impresores" 36 .

Al referirse a las Gacetas de Paula Benavides, Amor de Fournier opina: "No deja de ser un título de orgullo para la mujer, el que sea un nombre femenino el que figura al pie de los primeros periódicos publicados en nuestro país" ${ }^{\text {37. }}$. Así pues, la inculturación fue una realidad encabezada en gran medida por las mujeres.

35 García ICAZBAlCETA, J. (1954) Tipografía mexicana, México, UNAM; tan sólo del siglo XVI ofrece un catálogo de 44 impresiones (pp. 205-230).

36 Ibid.

${ }^{37}$ AMOR DE FOURNIER, (1972), ob. cit., p. 6. 
¿Qué implica hablar de inculturación? Implica en cierta forma la asunción de un concepto monolítico de cultura como un sistema cuyas fronteras son discernibles, que, desde la antropología clásica de la mano de Taylor ha sido ampliamente difundido y con el que operan prioritariamente los historiadores. Pero, con el fin de cuestionar la idea de una cultura como una forma de totalidad, que sugiere una visión demasiado consensual de la misma, es preciso acudir a E. P. Thompson quien alerta sobre el hecho de que "el mismo término "cultura" con su agradable invocación de consenso, puede servir para distraer la atención de las contradicciones sociales y culturales, de las fracturas y las oposiciones dentro del conjunto" 38 .

Por consiguiente, el asunto no es tan simple como la imagen de una cultura autocontenida que se traslada como tal a otro espacio, hay procesos de reacomodación muy complejos, de nuevo, los espacios intermedios. Así, los límites, las fronteras que separan a las culturas no son particiones impermeables. Para el caso del período colonial, bajo la polaridad indio-español, se encuentra que las formas de dominación no actúan exclusivamente entre indígenas y españoles, sino que en el interior de este último grupo había pobres y marginados, de la misma forma que las sociedades indígenas eran altamente jerarquizadas. Por otra parte, entre estos conglomerados -como prefiere llamarlos Gruzinski ${ }^{39}$ - se da un acto complejo que genera afectos fronterizos e identificaciones, tipos peculiares de simpatía y choque cultural cuyos confines se encuentran hasta tal punto imbricados que son inseparables. Lo mismo sucede al problematizar el concepto de mestizaje en el sentido que aquello que se mezcla no es un elemento puro, sino ya mestizado

\section{A MODO DE CONCLUSIÓN}

¿Podemos calificar a la mujer americana de esta época como mediadora cultural? Pienso que sí, aunque la mediadora cultural difícilmente puede ser definida de forma rígida o absoluta. Para los efectos de este texto se entiende como alguien que atraviesa las fronteras físicas e intelectuales de dos o más culturas, identificando nuevas realidades, analizándolas e incorporándolas en su cotidianidad. Usualmente estos individuos -en nuestro caso mujeres-, muestran una gran capacidad para aclimatarse en espacios, lenguas y culturas distintas, al tiempo que conservan elementos de sus culturas de origen.

Esta actitud les permite asumir el papel de difusores de prácticas culturales que, con frecuencia, se expanden no sólo en el medio en el que se radican, sino también

\footnotetext{
${ }^{38}$ Thompson, E.P. (1995), Costumbres en común, Barcelona, Editorial Crítica, p. 19.

${ }^{39}$ GruZINSKI, S. (2000), El pensamiento mestizo, Barcelona, Paidós, p. 312.
} 
en sus lugares de origen, como sucedió en España con los numerosos "regalos" traídos de América. Entre las diversas facetas relacionadas con el papel de los mediadores culturales está la de la movilidad, situación que les permite articular conocimientos de dos o más lugares, como resultado del proceso de desplazamiento al que se sometieron. En términos temporales, este contacto puede ser más o menos prolongado e incluye desde un individuo de paso hasta personajes que se establecieron en territorios nuevos y se sumergieron en otras culturas, iniciando un proceso de adaptación y asimilación, pero sin perder sus raíces.

Saberes e informaciones de diferente tipo y origen, prácticas producto de pensamientos y memorias distintas, que modificaban y desdibujaban la propia frontera. En su calidad de mediadora la mujer no sólo se apropió y utilizó lo que el nuevo espacio le ofrecía, sino que facilitó la transmisión de información entre sus vecinos, hombres y mujeres sin importar su origen y condición social. Llevando, recibiendo, tomando iniciativas, y propiciando comunicaciones e intercambios que la convirtieron no sólo en protagonista de esas mutaciones que se producían, sino en producto ella mismo de los encuentros y choques culturales ${ }^{40}$.

Aunque autores como Friedlander ${ }^{41}$, al sostener que la Conquista fue un proceso de "borrón y cuenta nueva", negaron la existencia de una tradición cultural indígena específica, numerosos estudios muestran la supervivencia de prácticas a nivel de la organización social y de importantes complejos de la cosmovisión que hunden sus raíces en la época prehispánica y la experiencia colonial. Los autores que recurren de manera acrítica a estas clasificaciones convencionales -en última instancia, definiciones forjadas por el Estado- olvidan tanto la historia local de las comunidades particulares y las complejidades de las identidades regionales, como la historia de las políticas gubernamentales; de este modo colaboran en el ocultamiento de un importante proceso de identidad forzada, que ha sido incluso calificado de «etnocidio».

${ }^{40}$ GRUZINSKI, Serge, (2005), «Passeurs y elites católicas en las Cuatro Partes del Mundo. Los inicios ibéricos de la mundialización (1580-1640)», en O'PHELAN GODOY, Scarlett y SALAZAR-SOLER, Carmen (eds.), Passeurs mediadores culturales y agentes de la primera globalización en el Mundo Ibérico, siglos XVI-XIX, Lima, Instituto Francés de Estudios Andinos, Instituto Riva-Agüero, pp. 1316.

${ }^{41}$ Friedlander J. (1997), Ser indio en Hueyapan. Un estudio de identidad obligada en el México contemporáneo, México, Fondo de Cultura Económica. 
